\title{
Global monitoring of average volume of alcohol consumption
}

\author{
Rehm, J ; Eschmann, S
}

\begin{abstract}
OBJECTIVES: To estimate the prevalence of different categories of average volume of alcohol consumption for World Health Organization (WHO) regions. To check how the monitored indicator of average volume relates to prevalence of alcohol dependence. To discuss conclusions for establishing a global monitoring system. METHODS: Prevalence of different categories of average volume of alcohol consumption was estimated by a triangulation of survey results, production, and sales figures. The relation between average volume of consumption and prevalence of alcohol dependence was analysed by regression techniques. RESULTS: Alcohol consumption varies widely by sex, age, and region. It can predict prevalence of dependence with about $74 \%$ of the variation of the latter explained. CONCLUSIONS: With current data, global monitoring of alcohol is possible. However, more and better surveys are necessary for the future. They should include patterns of drinking to improve prediction of other health outcomes like coronary heart disease (CHD) and accidents.
\end{abstract}

DOI: https://doi.org/10.1007/BF01318406

Posted at the Zurich Open Repository and Archive, University of Zurich

ZORA URL: https://doi.org/10.5167/uzh-94682

Journal Article

Published Version

Originally published at:

Rehm, J; Eschmann, S (2002). Global monitoring of average volume of alcohol consumption. Sozial- und Präventivmedizin, 47(1):48-58.

DOI: https://doi.org/10.1007/BF01318406 
1 Addiction Research Institute, Zurich

2 Centre for Addictions and Mental Health, Toronto

${ }^{3}$ Department of Public Health Sciences, University of Toronto

\section{Global monitoring of average volume of alcohol consumption}

\section{Summary}

Objectives: To estimate the prevalence of different categories of average volume of alcohol consumption for World Health Organization (WHO) regions. To check how the monitored indicator of average volume relates to prevalence of alcohol dependence. To discuss conclusions for establishing a global monitoring system.

Methods: Prevalence of different categories of average volume of alcohol consumption was estimated by a triangulation of survey results, production, and sales figures. The relation between average volume of consumption and prevalence of alcohol dependence was analysed by regression techniques.

Results: Alcohol consumption varies widely by sex, age, and region. It can predict prevalence of dependence with about $74 \%$ of the variation of the latter explained.

Conclusions: With current data, global monitoring of alcohol is possible. However, more and better surveys are necessary for the future. They should include patterns of drinking to improve prediction of other health outcomes like coronary heart disease (CHD) and accidents.

Keywords: Alcohol consumption - Prevalence - Dependence - Monitoring.

In a recent editorial of this journal, Morabia and Abel (2001) underlined the necessity to provide the basis for international comparisons of health determinants. Their arguments tie in with the current efforts of World Health Organization (WHO) to establish a global monitoring system of risk factors for chronic disease and to try to comparatively evaluate the impact of risk factors (for further informa- tion on the comparative risk analysis - CRA 2000 -, see http://www.ctru.auckland.ac.nz/CRA/main.html). Consumption of alcohol is one of the major health determinants (National Institute on Alcohol Abuse and Alcoholism 2000 ), related in different ways to more than $60 \mathrm{ICD}$ (International Statistical Classification of Diseases and Related Health Problems) categories (see Gutjahr et al. 2001). Alcohol has been included as one of 10 risk factors in the original Global Burden of Disease (GBD) Study (Murray \& Lopez 1996; Murray \& Lopez 1997) where the beneficial effects had been subtracted from the detrimental effects to come up with a net burden. Using this procedure, the disease burden attributable to alcohol (3.5\% of total disability adjusted life years - DALYs) was estimated higher than the disease burden of tobacco (2.6\%) (Murray \& Lopez 1997).

Given this impact, it is no surprise that alcohol consumption has been monitored regularly by the World Health Organization (1999). In addition, another UN organization, the Food and Agriculture Organization, and the alcohol industry (e.g., Productschap voor Gedistilleerde Dranken 2000), regularly monitor alcohol production and sales, albeit for different reasons. The purpose of this contribution is to combine these and other data sources to estimate prevalence of different categories of consumption and dependence in different parts of the world. It is based on previous efforts described in detail elsewhere (Rehm \& Gmel 2001). Specifically the paper has three main objectives:

- To estimate prevalence of different categories of average volume of alcohol consumption for WHO regions.

- To check how the monitored indicator of average volume related to prevalence of alcohol dependence.

- To discuss conclusions for establishing a global monitoring system. 


\section{Methods}

\section{Dimensions of alcohol consumption}

Alcohol as a risk factor has different dimensions, which are relevant for health. Two main dimensions have been identified as minimally necessary: average volume of consumption and drinking patterns (Rehm et al. 1996; Dawson 2000; Rehm et al. 2001 b). Unfortunately, most health surveys concentrate on average volume only. Thus, population survey information around the world is almost exclusively available for average volume only and patterns of drinking still have to be assessed using other methods (see Rehm et al. $2001 \mathrm{~b}$; Gmel et al. 2001). As a result, this paper concentrates on average volume of alcohol consumption.

\section{Classifying average volume of alcohol consumption}

Average volume of alcohol consumption, as many other health determinants (e.g., Murray \& Lopez 1999) is a continuous variable. However, based on epidemiological tradition, meta-analytical overviews on relationships between average volume and disease outcomes have been using the following categories (Gutjahr et al. 2001; English et al. 1995; Single et al. 1999; Gutjahr \& Gmel 2001); for a discussion of origin of these categories see (English et al. 1995; Holman et al. 1996):

- Abstaimer: defined as no drink of alcohol within last year

- Average volume drinking category I: for females 0$19.99 \mathrm{~g}$ pure alcohol daily; for males $0-39.99 \mathrm{~g}$ pure alcohol daily

- Average volume drinking category II: for females 20$39.99 \mathrm{~g}$ pure alcohol daily; for males $40-59.99 \mathrm{~g}$ pure alcohol daily

- Average volume drinking category III: for females $40 \mathrm{~g}$ pure alcohol and above; for males $60 \mathrm{~g}$ pure alcohol and above daily. ${ }^{1}$

${ }^{1}$ For comparison: a $75 \mathrm{cl}$. bottle of wine contains about $70 \mathrm{gm}$ of pure alcohol.
Note, that in this tradition average volume drinking categories are defined differently by sex. This categorisation of average volume makes it possible to derive different shapes of risk curves (e.g., linear, $\mathbf{J}$-shape, threshold etc.), but at the same time allows inclusion of data from studies that collected only categorical information on levels of alcohol consumption.

Data sources for average volume of alcohol consumption Two main sources exist for average volume of alcohol consumption: survey data and per capita consumption figures. Per capita and unrecorded consumption data were taken from the Global Status Report on Alcohol (World Health Organization 1999) and from the WHO data bank created by the Marin Institute for the Prevention of Alcohol and Other Drug Problems (California, USA) and currently maintained by the Swiss Institute for the Prevention of Alcohol and Drug Problems (Lausanne, Switzerland). The term "unrecorded consumption" refers to data that are not reflected in official sales and production of alcohol statistics such as homebrew or illegally produced alcohol. However, such consumption can be estimated either from surveys or indirectly from raw products that can be used to produce alcohol (Rehm et al. 2001a; Rehm et al. 2001b).

Surveys were also collected from this data bank, but additional surveys were accessed based on individual contacts and by announcing the CRA on a specific WHO listserve (Rehm et al. 2001a). The procedure to decide in cases where there was more than one source of information for surveys and per capita data is described in detail elsewhere (Rehm et al. 2001a). Basically, information was pooled once the criteria for quality like representativeness, large sample size, etc. were all fulfilled.

\section{Regions used}

The following 14 regions were defined by WHO, based on a clustering of mortality figures (see World Health Organization $2000 \mathrm{~b}$ for details).

\section{Region MP* Countries included}

Afr D Algeria, Angola, Benin, Burkina Faso, Cameroon, Cape Verde, Chad, Comoros, Equatorial Guinea, Gabon, Gambia, Ghana, Guinea, Guinea-Bissau, Liberia, Madagascar, Mali, Mauritania, Mauritius, Niger, Nigeria, Sao Tome and Principe, Senegal, Seychelles, Sierra Leone, Togo

Afr E Botswana, Burundi, Central African Republic, Congo, Côte d'Ivoire, Democratic Republic of the Congo, Eritrea, Ethiopia, Kenya, Lesotho, Malawi, Mozambique, Namibia, Rwanda, South Africa, Swaziland, Uganda, United Republic of Tanzania, Zambia, Zimbabwe 


\section{Region MP* Countries included}

Amr B Antigua and Barbuda, Argentina, Bahamas, Barbados, Belize, Brazil, Chile, Colombia, Costa Rica, Dominica, Dominican Republic, El Salvador, Grenada, Guyana, Honduras, Jamaica, Mexico, Panama, Paraguay, Saint Kitts and Nevis, Saint Lucia, Saint Vincent and the Grenadines, Suriname, Trinidad and Tobago, Uruguay, Venezuela

\begin{tabular}{|c|c|c|}
\hline Amr & $\mathbf{D}$ & Bolivia, Ecuador, Guatemala, Haiti, Nicaragua, Peru \\
\hline Emr & $\mathbf{B}$ & $\begin{array}{l}\text { Bahrain, Cyprus, Iran (Islamic Republic of), Jordan, Kuwait, Lebanon, Libyan Arab Jamahiriya, } \\
\text { Oman, Qatar, Saudi Arabia, Syrian Arab Republic, Tunisia, United Arab Emirates }\end{array}$ \\
\hline Emr & $\mathbf{D}$ & Afghanistan, Djibouti, Egypt, Iraq, Morocco, Pakistan, Somalia, Sudan, Yemen \\
\hline Eur & $\mathbf{A}$ & $\begin{array}{l}\text { Andorra, Austria, Belgium, Croatia, Czech Republic, Denmark, Finland, France, Germany, } \\
\text { Greece, Iceland, Ireland, Israel, Italy, Luxembourg, Malta, Monaco, Netherlands, Norway, } \\
\text { Portugal, San Marino, Slovenia, Spain, Sweden, Switzerland, United Kingdom }\end{array}$ \\
\hline Eur & $\mathbf{B}$ & $\begin{array}{l}\text { Albania, Armenia, Azerbaijan, Bosnia and Herzegovina, Bulgaria, Georgia, Kyrgyzstan, Poland, } \\
\text { Romania, Slovakia, Tajikistan, The Former Yugoslav Republic of Macedonia, Turkey, } \\
\text { Turkmenistan, Uzbekistan, Yugoslavia }\end{array}$ \\
\hline Eur & $\mathbf{C}$ & $\begin{array}{l}\text { Belarus, Estonia, Hungary, Kazakhstan, Latvia, Lithuania, Republic of Moldova, Russian } \\
\text { Federation, Ukraine }\end{array}$ \\
\hline Sear & $\mathbf{B}$ & Indonesia, Sri Lanka, Thailand \\
\hline Sear & $\mathbf{D}$ & Bangladesh, Bhutan, Democratic People's Republic of Korea, India, Maldives, Myanmar, Nepal \\
\hline Wpr & $\mathbf{A}$ & Australia, Brunei Darussalam, Japan, New Zealand, Singapore \\
\hline Wpr & $\mathbf{B}$ & $\begin{array}{l}\text { Cambodia, China, Cook Islands, Fiji, Kiribati, Lao People's Democratic Republic, Malaysia, } \\
\text { Marshall Islands, Micronesia (Federated States of), Mongolia, Nauru, Niue, Palau, Papua New } \\
\text { Guinea, Philippines, Republic of Korea, Samoa, Solomon Islands, Tonga, Tuvalu, Vanuatu, } \\
\text { Viet Nam }\end{array}$ \\
\hline
\end{tabular}

*: MP stands for pattern of mortality, with the following denotations: A: Very low adult, very low child mortality, B: low adult, low child, C: low child, high adult, D: high adult, high child, E: very high adult, high child.

**: $\mathrm{N}$ denotes the number of countries included in the region.

Strategy to triangulate different sources of information on average volume of alcohol consumption

The global burden of disease framework requires a disaggregated approach that involves estimating the burden separately by sex, age, and regions. Clearly, per capita per se cannot be used at it is not specific for sex and age. On the other hand, survey data is problematic for a number of reasons. First, survey data is globally not available. But even if it were available, it has important limitations due to both subjective tendencies of underreporting and to sampling. As moderate consumption is the norm in many countries, especially in Western established market economies, people often tend to underreport their consumption, e.g., by not including or downsizing heavy consumption occasions. As a result, most surveys there tend to cover only $50 \%-70 \%$ of the sales or production figures (Midanik 1988; Midanik \& Harford 1994; Rehm 1998). This is not uniformly so. Interestingly, there are indications that the recent changes in norms in Great Britain resulted in higher coverage rates, although there may be other reasons for this (Leifman 2002). Also, in countries, where heavy drinking occasions and abstinence are the norm rather than the exception, over-coverage has been reported (e.g. Mexico, see Rehm et al. 2001a). Still these are exceptions and under-coverage is very frequent and thus, in some countries taking surveys as a basis, would result in only half of the consumption being recognised. Descriptions of alcohol consumption would be grossly underestimating actual drinking behaviour and the impact of alcohol would be severely underestimated.

At this point, it should be noted that household-based sampling strategies also show underestimations of consumption, as groups not covered (e.g., hospitalised, homeless) have on average higher consumption. Thus, to accurately describe actual behaviour, survey data have to be corrected by other sources. And the best and most reliable alternative source of information in this respect are per capita data (see Rehm et al. $2001 \mathrm{a}$, for a discussion on reliability of different forms of per capita data).

Using per capita consumption data from production and sales plus unrecorded consumption as the first estimate of 
overall alcohol consumption, the following strategy was adopted to generate sex-age-specific prevalence rates for the WHO regions:

- Firstly, for each WHO region the average per capita consumption including unrecorded consumption for the population 15 and above was estimated as a populationweighted average of country-specific per capita consumption data. The weights were derived from the average population over age 15 in each country for all years after 1995 on the basis of UN population data. Country-specific per capita data were estimated for 131 countries.

- Secondly, country-specific survey data of the ratio of male/female consumption were used to proportionally allocate the overall per capita consumption into male and female per capita consumption. This assumes that there are no country-specific gender biases in reporting within one region. Such an assumption may be problematic for regions with many countries with different cultures, e.g., Afr D with both Moslem and non-Moslem regions.

- Thirdly, again based on surveys, the age-specific prevalence of drinking was calculated under the assumptions that the average per capita consumption and the proportions of male and female abstainers were correct. It should be noted that survey information on abstention was available for 63 countries, including almost all of the countries with populations larger than 100 million. This means that about $50 \%$ of the countries for which data were available on per capita consumption also had available survey data.

\section{Range of estimates and uncertainty analysis}

Uncertainty analysis is undertaken to give an indication on the variability of the estimated data (for a detailed description of procedures see Rehm et al. $2001 \mathrm{a}$ ). Classically, confidence intervals on prevalence are determined by sample size, assuming that the underlying individual data are representative for the region. However, for some regions we do not have probabilistic samples. As alcohol consumption is a social activity and can vary markedly from one country to another within a region, one cannot automatically assume that the countries without surveys would have the same alcohol distribution as the countries with surveys. Thus, the procedure based on sample size cannot be used for calculating a range around the point estimates of prevalence. Moreover, prevalence was derived both from aggregate (per capita consumption) and from individual level data in a triangulation of information, for which there is no statistical theory to derive confidence intervals.

The algorithms specified below were developed after intensive discussions with experts from the field. They are intended to reflect the quantity and quality of the underlying data sources (e.g., amount of survey data available, local case studies, knowledge about cultural and legal restrictions including probability of reinforcement of norms). Aggregate level data exist for all countries included. To estimate average volume of alcohol consumption, we propose to base uncertainty analysis on the amount of survey information available in a region. In looking at the range of estimates obtained, it should be noted that the procedure allowed for some boundaries even if no survey information existed. For example, with Muslim countries such as Pakistan, the per capita information set clear upper boundaries for the highest drinking categories. Most hypothetical distributions were not possible with the overall volume consumed in this country. These considerations led to the following proposals: Based on the percentage coverage of the population with underlying survey information for each region, different intervals around the point estimate were drawn, ranging from $+/-10 \%$ for regions, where more than $75 \%$ of the population was covered by surveys, to intervals of $+1-100 \%$ for regions without a survey.

This applies to both sexes, as most surveys include both males and females. We had to correct further based on per capita consumption for regions where certain distributions were not plausible (for region Emr B: maximum range of estimates for abstainers $+/-15 \%$; minimum: $+/-1 \%$; for Emr D: maximum range of estimates for abstainers $+/-10 \%$; minimum: $+/ 1 \%$; for Sear B: maximum range of estimates for abstainers $+/-10 \%$; minimum: $+/-1 \%$; for Sear $D$ and Wpr B: minimum: $+1-0.2 \%$; for definitions of regions see above). The result can be seen in the Appendix 1.

\section{Strategy on finding surveys to calculate prevalence of alcohol dependence}

In addition to using the WHO database, Medline searches were conducted on surveys on alcohol dependence. All surveys were included which measured dependence with a standardised and validated test (e.g., Composite International Diagnostic Interview, Diagnostic Interview Schedule, Alcohol Use Disorders Identification Test, etc.) using either ICD 10 or DSM criteria (either DSM III, DSM III-R, or DSM IV). This resulted in 180 different data points. The complete list with all citations is available upon request from the author. For this paper, lifetime diagnoses were excluded, as the aim was to compare prevalence and average consumption at the same time point. To arrive at the figures in Table 1, data were submitted together with estimates on case fatality (Harris \& Barraclough 1998) and duration to yield consistent estimates, using the software DISMOD (http://www.hsph.harvard.edu/organizations/bdu/dismod/ index.htm ). 
Table 1 Average volume of consumption and prevalence of dependence by sex and WHO region

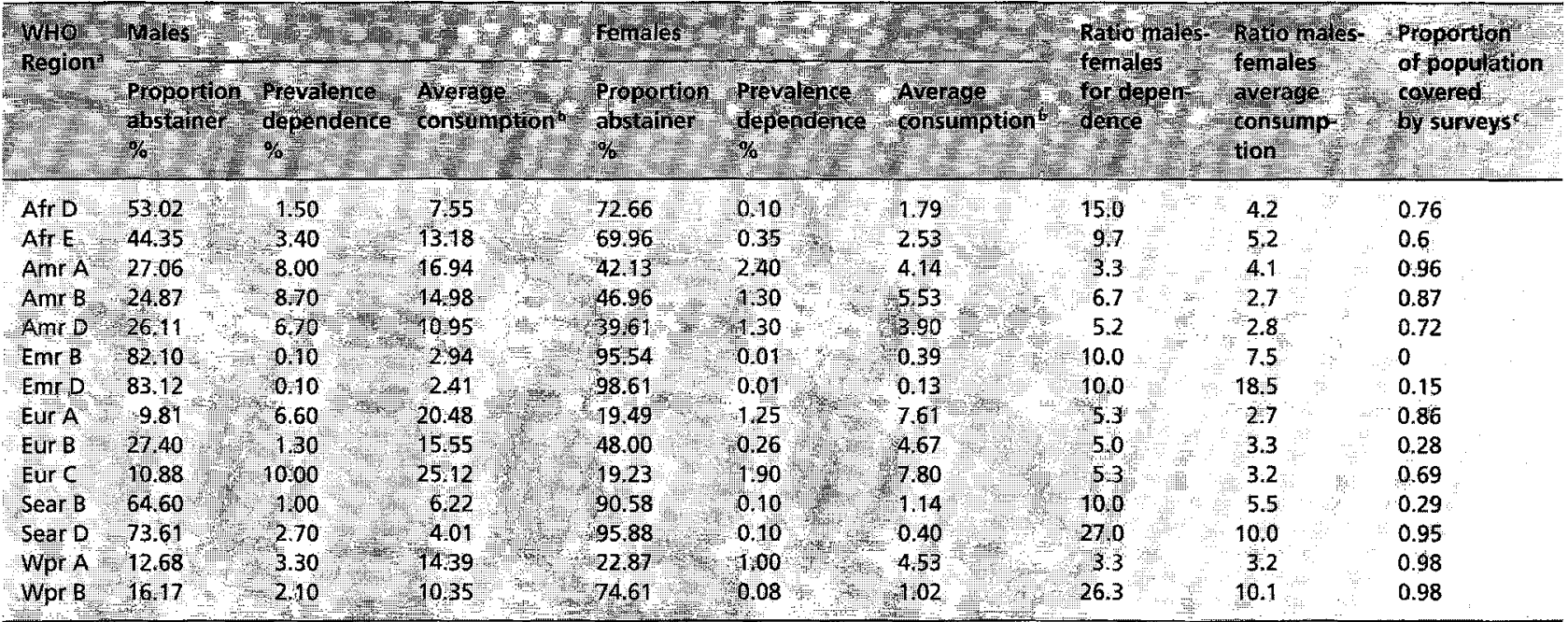

a Definition of WHO regions, see text.

b In g pure alcohol per day.

' If there was a survey with a probability sample in a country, the whole population of this country was seen as covered by surveys. The final proportion was calculated by the population (age 15 years and above) covered by surveys, divided by the total population (age 15 and above) for the respective region.

Please note that average volume of alcohol consumption and alcohol dependence were derived from non-overlapping datasets with different indicators and thus are statistically independent.

\section{Results}

Appendix 1 shows the main results for all WHO regions, separate by sex and age. It is interesting that huge differences in overall drinking persisted for the turn of the century, even though the general trend over the past decade was an increase in developing nations and a decrease in established market economies, which leads to a more similar level of average consumption (e.g., World Health Organization 1999). In addition, there are marked differences in the distribution between the drinking categories.

Also, the ratio in volume of alcohol consumed between males and females varies dramatically. On a country level, there are extremes like China with a ratio of 16:1 (Wei et al. 1999) on the one side (i.e., males consume 16 times more alcohol than females) and 3:1 in established market economies such as EU countries (Simpura \& Karlsson 2001). On a regional level there are the same differences with some of the estimates for regions with very low average volume of alcohol consumption being higher than for China (see Tab. 1).

To give a first estimate on how closely the average volume of alcohol consumption is related to one health outcome, the relationship between this variable and prevalence of alcohol dependence was assessed. Both variables co-vary to a con- siderable degree (Pearson's $r=0.86$ ). If dependence is predicted from average volume of consumption on the regional level, about $74 \%$ of the variation in prevalence of dependence can be predicted (see Fig. 1). As can be seen in Figure 1, the American regions tend to have higher than predicted dependence rates, whereas the European regions except Euro C (Russia) have lower than predicted dependence rate for males. For females, few of the regions fall outside the $95 \%$ confidence interval around the linear regression line, with North America (Amr A) being the most notable exception. Thus, if this relationship holds for countries or provinces' states within countries, monitoring average volume would be helpful in predicting dependence and planning health care facilities for this diagnosis. Aetiologically, dependence is related to heavy and uncontrolled drinking. On the other hand, per capita consumption depends very heavily on heavy drinkers as in most societies. In Switzerland, for instance, $11 \%$ of the adults are responsible for $50 \%$ of the overall consumption (Schweizerische Fachstelle für Alkohol- und andere Drogenprobleme 1999). In the US, the proportion responsible for half of the consumption is even less, and $20 \%$ of the adults drink about $90 \%$ of the total amount of alcohol consumed (Greenfield \& Rogers 1999). To give an example outside of established market economies: in China, $12.5 \%$ of the drinkers consumed $60 \%$ of all alcohol consumed (Wei et al. 1999). Thus, a strong relationship between average volume of alcohol consumption and prevalence of alcohol dependence was theoretically expected. 


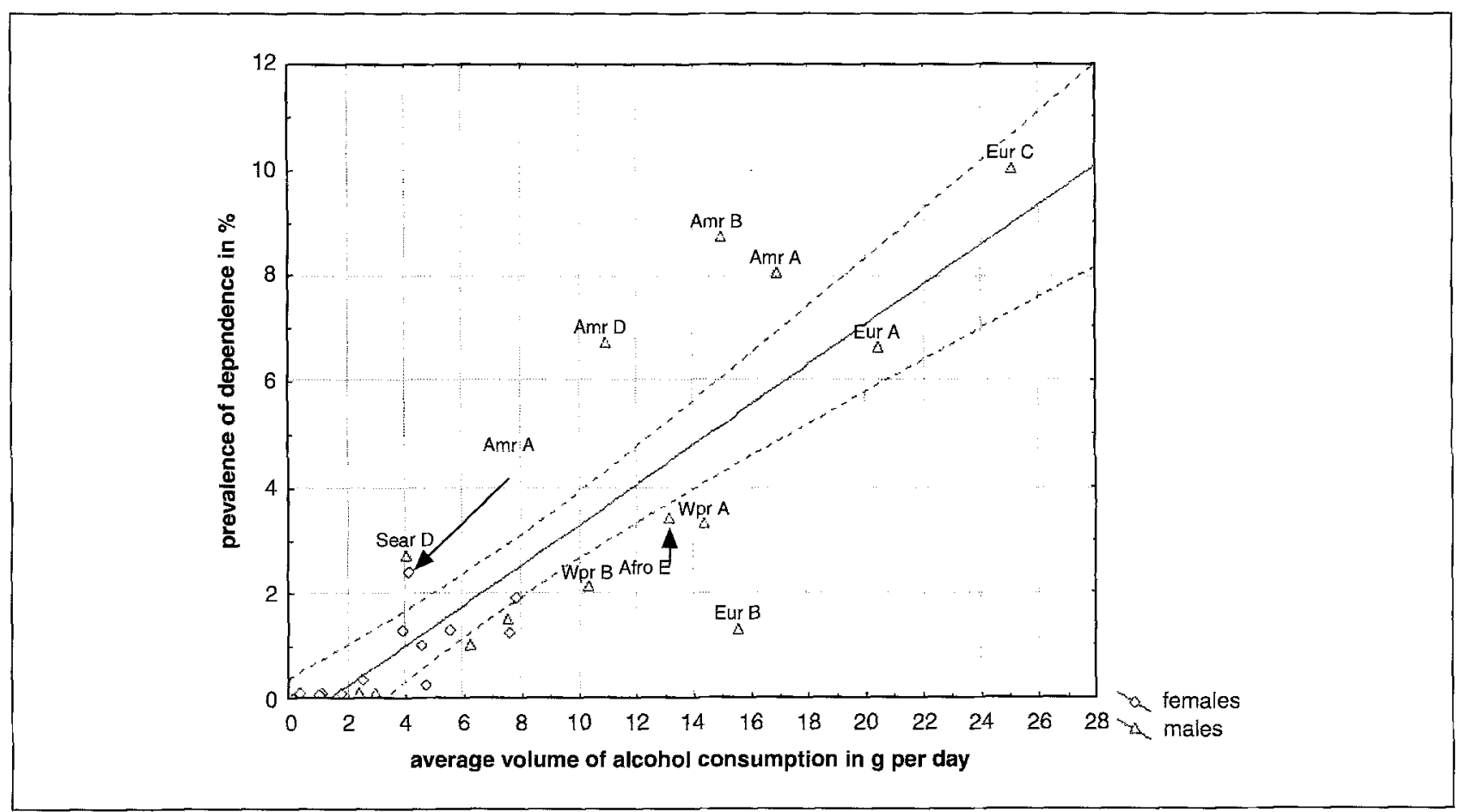

Figure 1 Alcohol dependence by average volume of alcohol consumption

\section{Conclusions}

It was shown that there is sufficient information to estimate average volume of alcohol consumption in different categories separate by sex and age for all regions of the world for the late 1990s. However, information became scarce in some regions of the world, notably in Muslim countries in North Africa, the Mid-East and the Far East (see Tab. 1). Also for the former socialist economies of Europe (Eur B), there is not enough recent information. As alcohol consumption is closely related to detrimental health outcomes, it should be monitored globally. Surveys should play an important part of this monitoring, but, as argued before, surveys alone are not enough. Subjective norms and usual sampling techniques lead to marked biases in estimating average consumption by surveys alone. As a result the estimates should be cross-validated with sales and production statistics. As production and sales figures are available on a global level, their inclusion in a continuous monitoring of average volume of alcohol consumption seems possible.

The quality of underlying surveys varied, and it would help in the future, if common standards of assessment were established (Rehm 1998; Dawson \& Room 2000). In addition, even though average volume of consumption is closely linked to many diseases (Gutjahr et al. 2001; English et al. 1995; Single et al. 1999; Gutjahr \& Gmel 2001), the links of this indicator to important other health outcomes are less pronounced. The beneficial effect of alcohol consumption on CHD for example depends on certain patterns of regular and moderate drinking (Puddey et al. 1999), which means that the same amount consumed in different ways results in different outcomes for CHD. The same is true for the large area of injuries, which is responsible for a large proportion of the disease burden attributable to alcohol (e.g., Murray \& Lopez 1996; English et al. 1995; Single et al. 1999; Gutjahr \& Gmel 2001). Thus, monitoring average volume of alcohol consumption is not enough. As a consequence, surveys including questions on average volume of alcohol consumption only should be enlarged to include measures for patterns of drinking, especially heavy drinking occasions. If questions on average volume and heavy drinking occasions were to be established as a minimal standard for assessing alcohol in health surveys, future monitoring of this health determinant could be even more helpful in shaping health policy (see World Health Organization 2000 a for a more thorough discussion on alcohol monitoring).

\section{Acknowledgements}

The WHO, the Swiss Federal Office of Public Health (contract \# 00.001588), the Addiction Research Institute in Zurich, Switzerland, and the Centre for Addiction and Mental Health in Toronto, Canada, financially supported this study. 
Zusammenfassung

Globales Monitoring des durchschnittlichen Alkoholkonsums Fragestellung: Schätzung der Prävalenz verschiedener Kategorien des Durchschnittskonsums von Alkohol für die Region nach Definition der Weltgesundheitsorganisation (WHO). Ermittlung der Beziehung zwischen Durchschnittskonsum und der Prävalenz von Alkoholabhängigkeit. Diskussion von Implikationen für ein globales Monitoringsystem.

Methoden: Die Prävalenz des Durchschnittskonsums von Alkohol wurde mittels der Triangulation von Survey-Daten, Produktions- und Verkaufszahlen geschätzt. Die Beziehung zwischen Durchschnittskonsum und Alkoholabhängigkeit wurde durch Regressionstechniken ermittelt.

Ergebnisse: Durchschnittlicher Alkoholkonsum variiert weltweit nach Geschlecht, Alter und Region. Der Durchschnittskonsum kann die Prävalenz von Alkoholabhängigkeit gut vorhersagen mit $74 \%$ erklärter Varianz.

Schlussfolgerungen: Die derzeitigen Daten erlauben ein globales Monitoring des durchschnittlichen Alkoholkonsums. Dennoch sind für die Zukunft mehr und bessere Surveys notwendig. Diese Surveys sollten auch Trinkmuster mit einschliessen, um auch andere Gesundheitsindikatoren als Abhängigkeit wie koronare Herzkrankheiten oder Unfälle besser vorhersagen zu können.
Résumé

Monitoring global de consommation moyenne d'alcool

Objectifs: Estimer la prévalence de différentes catégories de volume moyen de consommation d'alcool dans les régions de l'Organisation Mondiale de la Santé (OMS). Examiner si les indicateurs de monitoring du volume moyen sont corrélés à la prévalence de la dépendance à l'alcool. Discuter les implications pour un système de monitoring global.

Méthodes: La prévalence de différentes catégories de volume moyen de consommation d'alcool a été estimée à partir de données provenant d'enquêtes et de statistiques de production et de vente. La relation entre le volume moyen de consommation et la prévalence de la dépendance à l'alcool a été analysée par des techniques de régression linéaire.

Résultats: La consommation de l'alcool varie selon le sexe, l'âge et la région. La consommation peut prédire la prévalence de dépendance pour environ $74 \%$ de la variance expliquée.

Conclusions: Un système de monitoring global de la consommation moyenne d'alcool est possible avec les données courantes. Pourtant, de nouvelles enquêtes sont nécessaires. Elles doivent inclure des profils de consommation pour améliorer la prédiction d'autres indicateurs de santé, comme par exemple l'infarctus du myocarde et les accidents.

\section{References}

Dawson $D$ (2000). Measuring alcohol consumption. J Subst Abuse; 12 (special issue) 1-212.

Dawson $D$, Room $R$ (2000). Towards agreement on ways to measure and report drinking patterns and alcohol-related problems in adult general population surveys: the Skarpö Conference overview. J Subst Abuse 12 (special issue): $1-21$.

English D, Holman D, Milne E, et al. (1992). The quantification of drug caused morbidity and mortality in Australia. Canberra: Commonwealth Department of Human Services, 1995.

Gmel G, Rehm J, Frick U (2001). Methodological approaches to conducting pooled cross-sectional time series analysis: the example of the EU states. Eur Addict Res 7: 128-37.

Greenfield TK, Rogers $J D$ (1999). Who drinks most of the alcohol in the US: the policy implications. J Stud Alcohol 60: 78-89.
Gutjahr E, Gmel G (2001). Die sozialen Kosten des Alkoholkonsums in der Schweiz: epidemiologische Grundlagen 1995-1995.

Lausanne: Schweizerische Fachstelle für Alkohol- und andere Drogenprobleme (SFA). (Report; Nr. 36).

Gutjahr E, Gmel G, Rehm J (2001). The relation between average alcohol consumption and disease: an overview. Eur Addict Res 7: 117-27.

Harris EC, Barraclough B (1998). Excess mortality of mental disorder. Br J Psychiatry 173 : $11-53$.

Holman C, English D, Milne E, Winter M (1996). Meta-analysis of alcohol and all-cause mortality: a validation of NHMRC recommendations. Med J Aust 164: 141-45.

Leifman $H$ (2002). Validity problems in alcohol surveys with special emphasis on the comparative six-country ECAS survey. Contemp Drug Prob (in press)
Midanik L (1988). Validity of self-reported alcohol use: a literature review and assessment. $\mathrm{Br} J$ Addict 83: 1019-29.

Midanik L, Harford T (1994). Overview of alcohol consumption measurement papers. Addiction 89: 393-4.

Morabia A, Abel T (2001). International comparison of health determinants. Soz. Praven tivmed $46: 5$.

Murray C, Lopez A (1996). Quantifying the burden of diseas and injury attributable to ten major risk factors. In: Murray C, Lopez A, eds. The global burden of disease: a comprehensive assessment of mortality and disability from diseases, injuries and risk factors in 1990 and projected to 2020. Boston: Harvard School of Public Health on behalf of the World Health Organization and the World Bank: 295-324.

Murray C, Lopez A (1997). Global morality, disability, and the contribution of risk factors: global burden of disease study. Lancet 349 : 1436-42. 
Murray C, Lopez A (1999). On the comparable quantification of health risks: lessons from the Global Burden of Disease Study. Epidemiology 10: 594-605.

National Institute on Alcohol Abuse and Alcoholism (2000). 10th special report to the U.S. Congress on alcohol and health. Washington, DC: U.S. Department of Health and Human Services.

Productschap voor Gedistilleerde Dranken (2000). World drink trends, 2000: international beverage consurnption and production trends. Schiedam: NTC.

Puddey I, Rakic V, Dimmitt S, Beilin L (1999). Influence of pattern of drinking on cardiovascular disease and cardiovascular risk factors: a review. Addiction 94: 649-63.

Rehm J (1998). Measuring quantity, frequency and volume of drinking. Alcohol Clin Exp Res 22: 4S-14S.

Rehm J, Ashley M, Room R, et al. (1996). Drinking patterns and their consequences: report from an international meeting. Addiction 97: 1615-21.
Rehm J, Gmel G (2001). Alcohol, illicit drugs and the global burden of disease. Eur Addict Res 12 (special issue): 95-157.

Rehm J, Gmel G, Room R, et al. (2001a). Alcohol as a risk factor for burden of disease. Geneva: WHO.

Rehm J, Monteiro M, Room R, et al. (2001b). Steps towards constructing a global comparative risk analysis for alcohol consumption: determining indicators and empirical weights for patterns of drinking, deciding about theoretical minimum, and dealing with different consequences. Eur Addict Res 7 (3, special issue): 138-47.

Schweizerische Fachstelle für Alkohol- und andere Drogenprobleme (1999). Zahlen und Fakten zu Alkohol und anderen Drogen. Lausanne: SFA.

Simpura J, Karlsson $T$ (2001). Trends in drinking patterns among adult population in 15 European countries, 1950 to 2000: a review. Nordic Stud Alcohol Drugs 18 (Englisb suppl): 31-53.

Single E, Robson L, Rehm J, Xie X (1999). Morbidity and mortality attributable to alcohol, tobacco, and illicit drug use in Canada. Am J Public Health 89: 385-90.
Wei H, Derson $Y$, Shuiyuan $X$, Lingiiang $L$, Yalin $Z$ (1999). Alcohol consumption and alcohol-related problems: Chinese experience from six area samples, 1994. Addiction;94: 1467-76.

World Health Organization (1999). Global status report on alcohol. Geneva: WHO.

World Health Organization (2000a). International guide for monitoring alcohol consumption and related harm. Geneva: WHO, Department of Mental Health and Substance Dependence.

World Health Organization (2000b). The World Health Report 2000: health systems: improving performance. Geneva: WHO.

Address for correspondence
Prof. Dr. Jürgen Rehm
Addiction Research Institute
Konradstrasse 32
P.O. Box
CH-8031 Zurich
e-mail: jtrehm@isf.unizh.ch
or jtrehm@aol.com


Appendix 1 Prevalence of different categories for average volume of alcohol consumption in WHO regions ${ }^{b}$

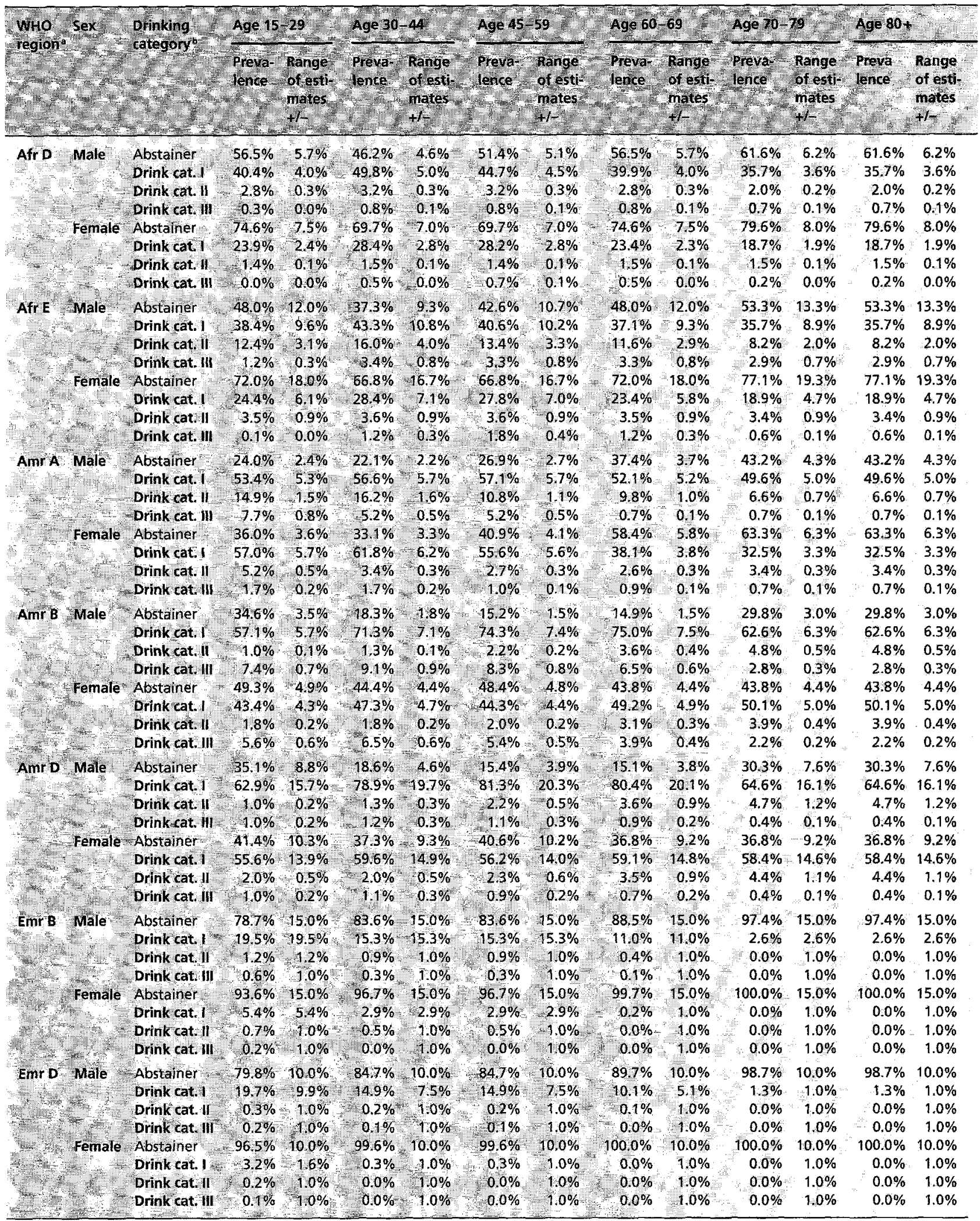


Appendix 1 (continued)

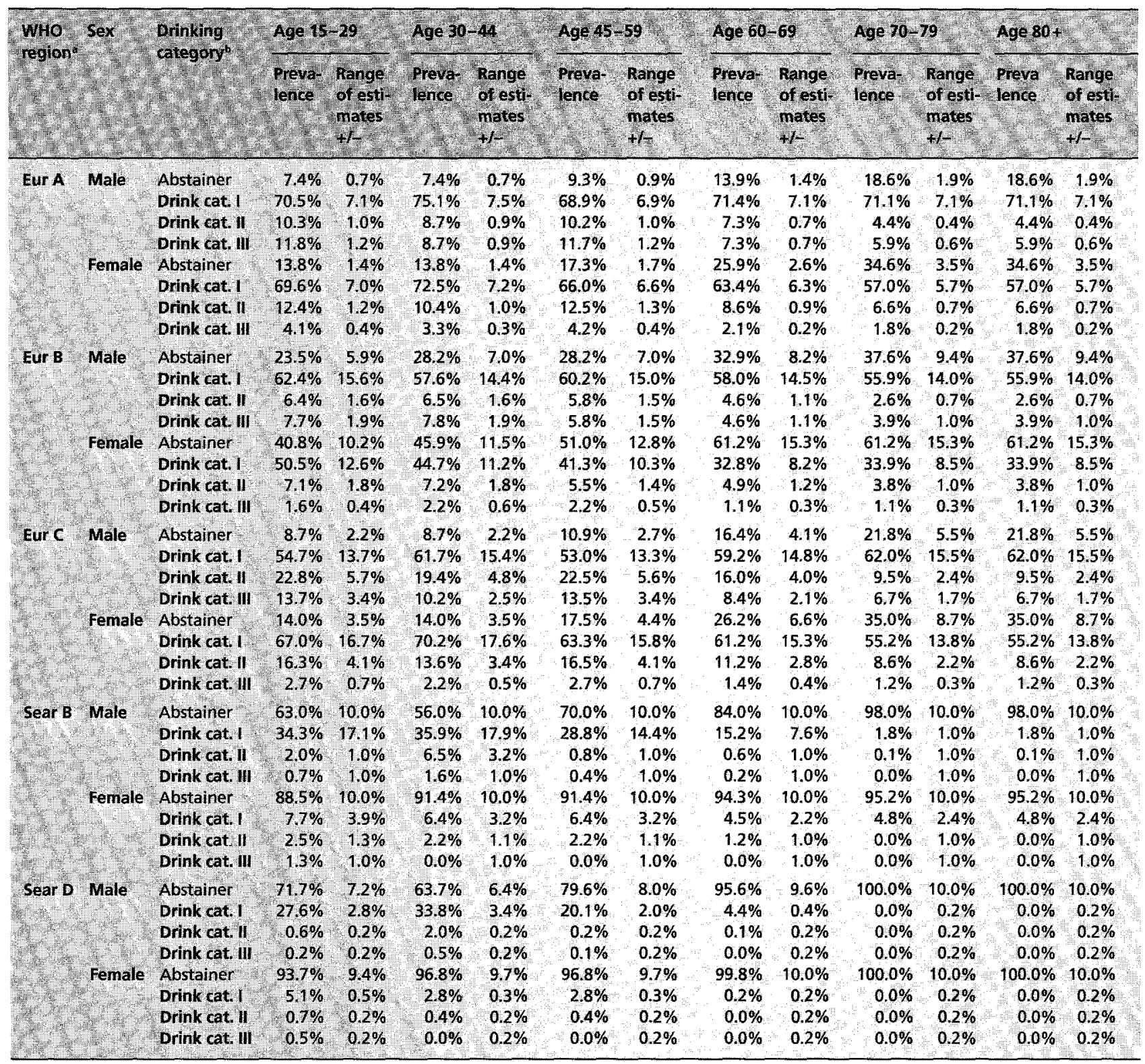


Appendix 1 (continued)

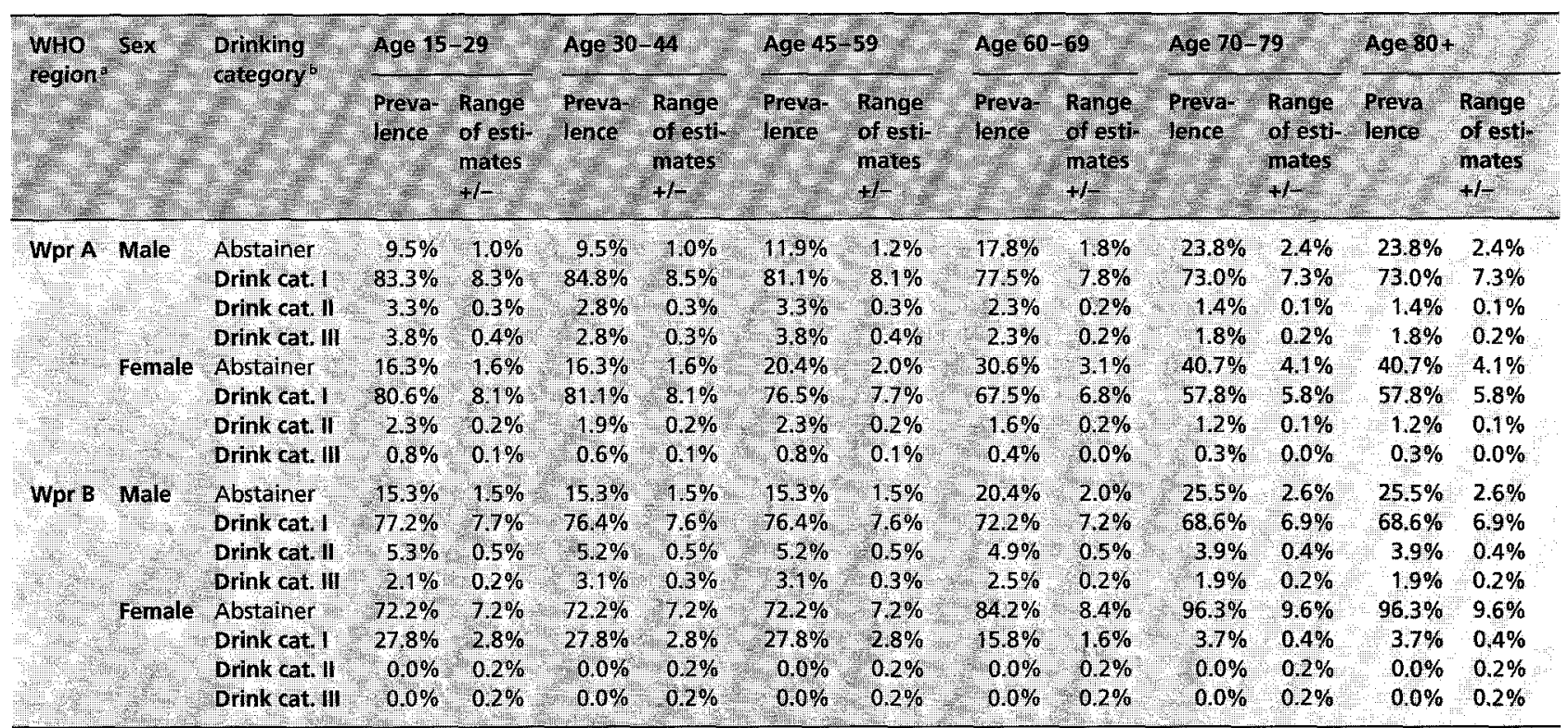

a Definition of WHO regions, see text.

b For explanation of drinking categories and calculation of ranges of estimates, see text. 